\title{
METODE INCREMENTAL DALAM MEMBANGUN APLIKASI IDENTIFIKASI GAYA BELAJAR UNTUK MENINGKATKAN HASIL BELAJAR SISWA
}

\author{
Muhamad Syarif ${ }^{1}$, Wahyu Nugraha ${ }^{2}$ \\ ${ }^{1,2}$ Program Studi Sistem Informasi, Universitas BSI, Pontianak \\ ${ }^{1,2}$ Universitas BSI Pontianak/Sistem Informasi; Jl. Abdurahman saleh No 18a \\ Email: ${ }^{1}$ muhamad.mdx @bsi.ac.id, ${ }^{2}$ wahyu.whn@bsi.ac.id
}

\begin{abstract}
Abstrak
Belajar dapat diartikan sebagai proses dari suatu individu yang mengalami perubahan perilakunya akibat bertambahnya pengalaman. Kemampuan seseorang dalam memahami dan menyerap informasi ketika proses belajar pasti berbeda tingkat waktunya, ada yang cepat, sedang maupun lambat. Perbedaan kecepatan ini dipengaruhi beberapa faktor, salah satu faktornya adalah cara atau gaya belajar dari individu tersebut. Gaya belajar memiliki 3 jenis yaitu visual, audio dan kinestetik, pelajar dapat mengetahui gaya belajar yang sesuai dengan cara melakukan tes dengan menjawab pertanyaan-pertanyaan yang berkaitan dengan cara belajar individu. Tujuan penelitian ini yaitu membuat aplikasi identifikasi gaya belajar berbasis web menggunakan metode incremental. Diharapkan dengan adanya penelitian ini dapat memberikan kontribusi kepada pelajar agar menemukan gaya belajarnya dan berdampak pada pemahaman menyerap informasi ketika proses belajar lebih cepat.
\end{abstract}

Kata kunci : gaya belajar, visual, audio, kinestetik, metode incremental

\begin{abstract}
Learning can be interpreted as the process of an individual who experiences changes in behavior due to increased experience. The ability of a person to understand and absorb information when the learning process must be different levels of time, some are fast, medium or slow. This speed difference is influenced by several factors, one of the factors is the way or learning style of the individual. Learning styles have 3 types, namely visual, audio and kinesthetic, students can find out the appropriate learning style by doing tests by answering questions related to individual learning methods. The purpose of this study is to create a web-based learning style identification application using incremental methods. It is expected that this research can contribute to students to find their learning styles and have an impact on understanding absorbing information when the learning process is faster.
\end{abstract}

Keywords : learning style, visual, audio, kinesthetic, incremental methods

\section{PENDAHULUAN}

Belajar dapat didefinisikan sebagai suatu proses di mana suatu organisasi berubah perilakunya sebagai akibat pengalaman. Belajar menyangkut perubahan dalam suatu organisme. Hal ini berarti bahwa belajar membutuhkan waktu [1]. Kemampuan seseorang untuk memahami dan menyerap pelajaran pada saat proses belajar sudah pasti berbeda tingkatnya, ada yang cepat, sedang dan ada pula yang sangat lambat. Perbedaan kecekatan, cara bekerja, kecenderungan terhadap soal-soal intelektual dan terhadap hal-hal yang estetis [2].

Keberhasilan belajar ditandai adanya perubahan-perubahan pada diri siswa menjadi lebih baik. Perubahan itu antara lain perubahan pola pikir, perasaan, pemahaman, dan tingkah laku secara umum. Keberhasilan belajar siswa dipengaruhi oleh beberapa faktor, antara lain: intelegensi, minat, bakat, 
keadaan sosial ekonomi, perhatian orang tua, metode mengajar, media, kurikulum, kesiapan, dan teman bergaul [2].

Suatu proses belajar mengajar seorang guru hanya menyajikan materi secara langsung dan hanya berfokus pada satu metode pembelajaran saja tanpa mengidentifikasi dan memahami kondisi belajar peserta didik, sehingga pembelajaran tidak berjalan dengan efektif, akibatnya hasil belajar tidak sesuai dengan yang diharapkan, padahal guru sebagai tenaga pengajar sangat mempengaruhi hasil belajar peserta didik [3]. Berbagai penelitian tentang metode mengajar yang sesuai dalam proses belajar mengajar ternyata sampai sekarang masih diragukan keberhasilannya, karena setiap metode mengajar bergantung pada cara atau gaya belajar siswa, pribadinya serta kemampuannya [4].

Gaya Belajar merupakan suatu kombinasi dari bagaimana seseorang menyerap dan kemudian mengatur serta mengolah informasi. Gaya belajar bukan hanya berupa aspek ketika menghadapi informasi, melihat, mendengar, menulis dan berkata tetapi juga aspek pemrosesan informasi sekunsial, analitik, global atau otak kiri dan otak kanan. Aspek lain adalah ketika merespon sesuatu atas lingkungan belajar (diserap secara abstrak dan konkret) [5]. Gaya belajar merupakan modalitas belajar yang sangat penting karena salah satu karakteristik yang mempengaruhi hasil belajar dikarenakan gaya belajar yang sesuai terhadap individu tersebut. Menerapkan gaya belajar yang sesuai akan menarik minat pelajar melakukan aktivitas belajar, baik ketika belajar secara individu maupun berkelompok.

Pada sebuah buku mengenai quantum learning disebutkan bahwa gaya belajar ada 3 macam, yaitu visual, auditorial dan kinestetik [6]. Identik dari ketiga gaya belajar tersebut adalah:
1. Gaya belajar Visual Learners: Tipe gaya belajar yang paling baik melalui penglihatan.

2. Gaya belajar Auditory Learnears: Tipe gaya belajar yang paling baik melalui pendengaran.

3. Gaya belajar Kinesthetik learner: Tipe gaya belajar yang paling baik melalui pergerakan secara fisik.

Berdasarkan permasalahan diatas peneliti akan merancang dan membuat aplikasi untuk mengidentifikasi gaya belajar seorang pelajar agar dapat mengetahui tipe gaya belajar mana yang paling sesuai dengan dirinya, diharapkan dengan mengetahui gaya belajar seorang siswa dapat meningkatkan hasil belajar akademiknya. Metode incremental dipilih sebagai metode pengembangan perangkat lunak karena metode ini dianggap mampu mengamodasikan perubahan secara fleksibel dan memiliki resiko yang lebih rendah terhadap proses pengembangan sistem.

\section{TINJAUAN PUSTAKA}

Pada bagian ini akan dijelaskan beberapa tinjauan pustaka yang berkaitan dengan penelitian.

\subsection{Belajar}

Belajar bisa dimaknai sebagai suatu proses aktif untuk menuju satu arah tertentu sehingga dapat meningkatkan perbuatan, kemampuan atau pengertian mengenai sesuatu yang baru [7]. Pada penelitian Chania dkk mengatakan bahwa dalam belajar setiap individu memiliki kecenderungan kepada salah satu cara atau gaya tertentu. Kecenderungan atau gaya seseorang ini disebut gaya belajar [8].

\subsection{Gaya Belajar}

Gaya belajar merupakan sebuah pendekatan yang menjelaskan mengenai bagaimana individu belajar atau cara yang ditempuh oleh masing-masing orang untuk 
berkonsetrasi pada proses, dan menguasai informasi yang sulit dan baru melalui persepsi yang berbeda. Gaya bersifat individual bagi setiap orang, dan untuk membedakan orang yang satu dengan orang lain. Hal ini menyiratkan bahwa setiap pelajar memiliki perbedaan cara atau kebiasaan belajar terutama dalam hal yang berkaitan dengan informasi [9].

Selain itu berdasarkan penelitian yang pernah dilakukan sebelumnya menunjukkan bahwa "para peneliti menemukan adanya berbagai gaya belajar pada siswa yang digolongkan menurut kategori-kategori tertentu" [10]. Mereka berkesimpulan:

1. Tiap murid belajar menurut cara sendiri yang kita sebut gaya belajar.

2. Kita dapat menemukan gaya belajar itu dengan instrumen tertentu.

3. Kesesuian gaya mengajar dengan gaya belajar mempertinggi efektivitas belajar.

\subsection{Jenis Gaya Belajar}

Gaya belajar kedalam 3 bagian, yaitu visual learners, auditory leaners, dan kinesthetik learners. Adapun perbedaan dari ketiga jenis gaya belajar tersebut adalah sebagai berikut [6]:

1. Visual Learners

Peserta didik visual adalah mereka yang belajar paling baik melalui penglihatan. Peserta didik visual memiliki kesulitan menyerap informasi melalui presentase verbal tanpa disertai dengan gambargambar visual. Kekuatan mereka adalah visual, oleh karena itu perlu ada alat bantu visual atau alat peraga yang dapat mereka lihat dan saksikan secara langsung.

Ciri-ciri gaya belajar visual adalah:

a. Lebih mudah mengingat dengan cara melihat.

b. Tidak terganggu oleh suara ribut atau berisik.

c. Lebih suka membaca.

d. Suka mendemonstrasikan sesuatu daripada penjelasan.
Kendala dalam gaya belajar visual seperti terlambat menyalin pelajaran dipapan tulis, dan tulisannya berantakan sehingga tidak mudah terbaca. Siswa yang mempunyai gaya belajar visual umumnya lebih suka melihat daripada mendengarkan, umumnya mereka cenderung teratur, rapi dan berpakaian indah.

2. Auditory Learners

Peserta didik auditorial adalah mereka yang belajar sesuatu paling baik melalui pendengaran. Jenis gaya belajar ini cenderung menyukai penyajian material lewat ceramah dan diskusi. Bahkan bagi orang dewasa yang bergaya belajar auditori mampu mengingat informasi yang disajikan melalui ceramah selama berjam-jam dalam waaktu yang relatif lama. Dari segi memproses informasi, kekuatan daya penerimaan mereka melalui pendengaran sehingga mereka dapat menganalisis kata demi kata.

Ciri -ciri gaya belajar auditorial, antara lain:

a. Mudah mengingat dari apa yang didengarkannya.

b. Tidak bisa belajar dalam suasana ribut atau berisik.

c. Lebih menyukai diskusi atau juga cerita.

d. Bisa mengulangi apa yang didengarkan.

Kendala dalam gaya belajar auditorial ini adalah anak sering lupa apa yang dijelaskan guru, sering keliru apa yang disampaikan oleh guru, dan juga sering lupa membuat tugas yang diperintahkan melalui lisan. Siswa yang menyukai gaya belajar auditorial umumnya tidak suka membaca buku petunjuk. Dia lebih suka bertanya untuk mendapatkan informasi yang diperlukannya [6].

3. Kinesthetik Learners

Belajar kinestetik atau dikenal juga dengan istilah belajar taktil (berkenaan dengan perabaan) adalah gaya belajar dimana peserta didik melakukan aktivitas secara fisik. Dua hal penting yang sangat 
disenangi oleh mereka yang bergaya belajar kinestetik adalah sering bergerak atau berpindah selama pembelajaran berlangsung. secara fisik, mereka menggunakan fisik lebih banyak daripada melihat dan mendengarkan.

Ciri-ciri gaya belajar kinestetik:

a. Berbicara perlahan.

b. Penampilan rapi.

c. Tidak terlalu mudah terganggu dengan situasi keributan.

d. Belajar melalui memanipulasi dan praktek.

e. Menghapal degan cara berjalan dan melihat.

\subsection{Hubungan Metode dengan Gaya Belajar}

Suatu kesalahan besar jika guru memperlakukan peserta didik secara sama. Gaya belajar (learning style) seorang pelajar perlu diperhatikan, baik secara visual, auditorial, dan kinestettik [10]. Gaya belajar dapat menentukan prestasi belajar anak. Jika diberikan strategi yang sesuai dengan gaya belajarnya, anak dapat berkembang dengan lebih baik. Gaya belajar otomatis tergantung dari orang yang belajar. Artinya setiap orang mempunyai gaya belajar yang berbeda-beda [10].

\subsection{Hasil Belajar}

Snelbeker dalam penelitian Rusmono mengatakan bahwa "perubahan atau kemampuan baru yang diperoleh siswa setelah melakukan perbuatan belajar merupakan hasil belajar, karena belajar pada dasarnya adalah bagaimana perilaku seseorang berubah sebagai akibat dari pengalaman" [11]. Oleh karena itu, apabila siswa mempelajari pengetahuan tentang konsep, maka perubahan perilaku yang diperoleh adalah berupa penguasaan konsep.

\section{METODOLOGI PENELITIAN}

Pada penelitian ini peneliti melakukan dua tahapan metode, yaitu peneliti melakukan metode pengumpulan data dan metode pengembangan perangkat lunak.

\subsection{Metode Pengumpulan Data}

Teknik pengumpulan data merupakan langkah-langkah yang diperoleh peneliti untuk mendapatkan data dalam usaha pemecahan masalah penelitian. Adapun dalam pengumpulan data tersebut diperlukan teknik-teknik tertentu sehingga data yang diharapkan dapat terkumpul dan benar-benar relevan dengan permasalahan yang hendak dipecahakan. Teknik pengumpulan data pada penelitian ini menggunakan metode studi dokumen dimana dalam proses pengumpulan data peneliti menggunakan berbagai macam dokumen yang berguna sebagai bahan penelitian seperti buku-buku, makalah atau paper penelitian, dan karya ilmiah lainnya yang berkaitan dengan judul yang diangkat sebagai referensi. Informasi tersebut diambil dari berbagai sumber.

\subsection{Metode Pengembangan Perangkat Lunak}

Metode incremental merupakan salah satu metode pengembangan perangkat lunak yang mampu meminimalisir ketidak sesuaian dalam proses pengembangan perangkat lunak [12]. Pada metode increment, setiap tahapan yang ada dalam metodologi terdapat masukan (input) dan keluaran (output). Output dari proses increment akan dujadikan sebagai masukan (input) untuk proses increment selanjutnya. 


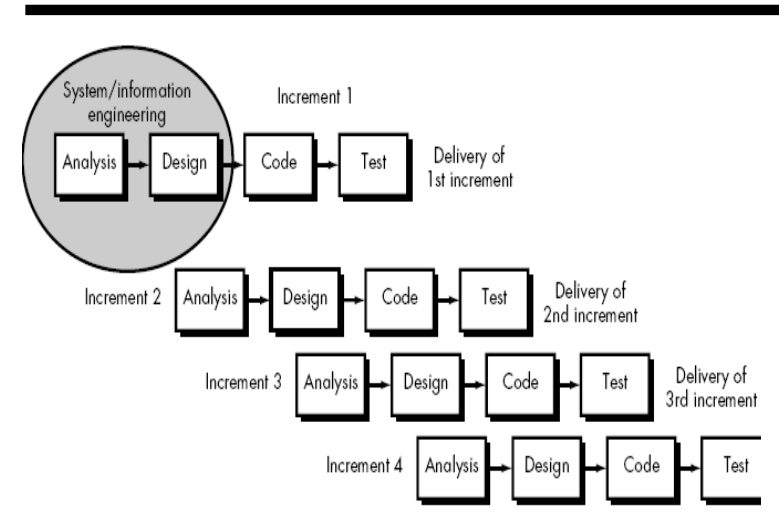

Gambar 1. Metode Incremental

\section{HASIL DAN PEMBAHASAN}

Pada bab ini peneliti akan menggambarkan hasil dari perancangan sistem melalui gambar, tabel, diagram, dan grafik. Sehingga gambaran tentang perancangan sistem yang diteliti ini dapat dimengerti dengan baik.

\subsection{Analisa Kebutuhan}

Rancangan penelitian aplikasi identifikasi gaya belajar memiliki kebutuhan fungsional dimana kebutuhan tersebut adalah tes yang terdiri dari pertanyaanpertanyaan yang terindentifikasi pada setiap jenis gaya belajar. Tes tersebut harus menghasilkan gaya belajar yang paling sesuai terhadap siswa yang telah melakukan tes berdasarkan jawaban yang dipilih. Selain itu diperlukan informasi lainnya yang berkaitan dengan gaya belajar, misalkan deskripsi, kelebihan serta kekurangan dari tiap gaya belajar agar dapat mengurangi kekurangan dan menambahkan kelebihan yang diperlukan.

\subsection{Rancangan Sistem}

Sistem identifikasi gaya belajar ini digambarkan dengan beberapa diagram untuk memberikan gambaran tentang sistem yang dirancang. Adapun diagram-diagram tersebut seperti usecase diagram, activity diagram, logical record structure, dan class diagram.

\subsubsection{Usecase Diagram}

Use Case diagram adalah diagram yang menggambarkan interaksi antara sistem dengan sistem eksternal pengguna. Perancangan use case pada penelitian ini adalah sebagai berikut:

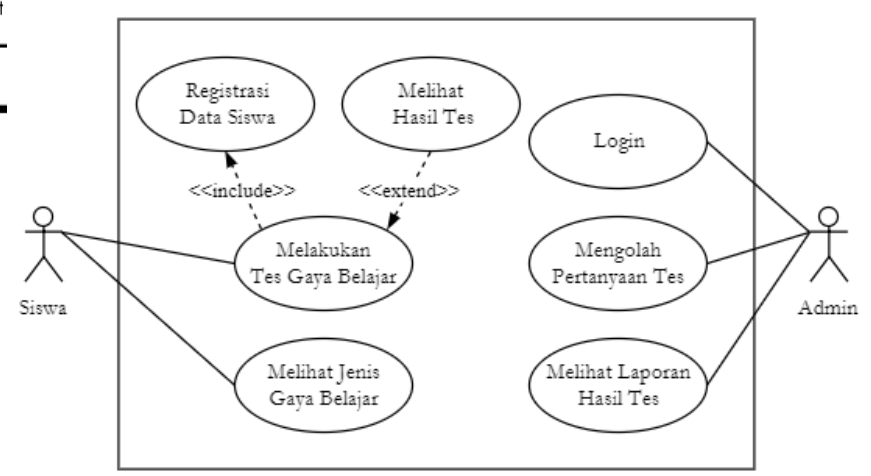

Gambar 2. Use Case Diagram

\subsubsection{Activity Diagram}

Diagram aktivitas atau activity diagram menggambarkan workflow (aliran kerja) atau aktivitas dari sebuah sistem atau proses bisnis atau menu yang ada pada perangkat lunak. Perancangan activity diagram pada penelitian ini adalah sebagai berikut:

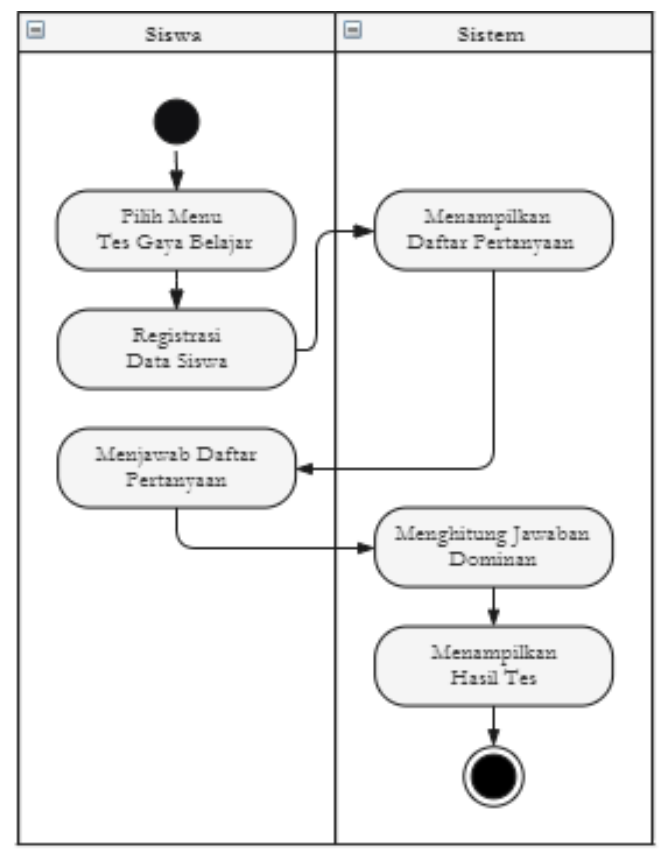

Gambar 3. Activity Diagram Tes Identifikasi Gaya Belajar 


\subsubsection{Logical Record Structure}

Logical record structure (LRS) merupakan hasil transformasi ERD ke LRS yang memulai proses kardinalitas dan menghilangkan atribut-atribut yang saling berelasi. LRS yang merupakan representasi dari struktur record-record pada tabel, dimana tabel-tabel tersebut terbentuk dari hasil himpunan antar entitas pada ERD. Rancangan LRS pada penelitian ini adalah sebagai berikut:

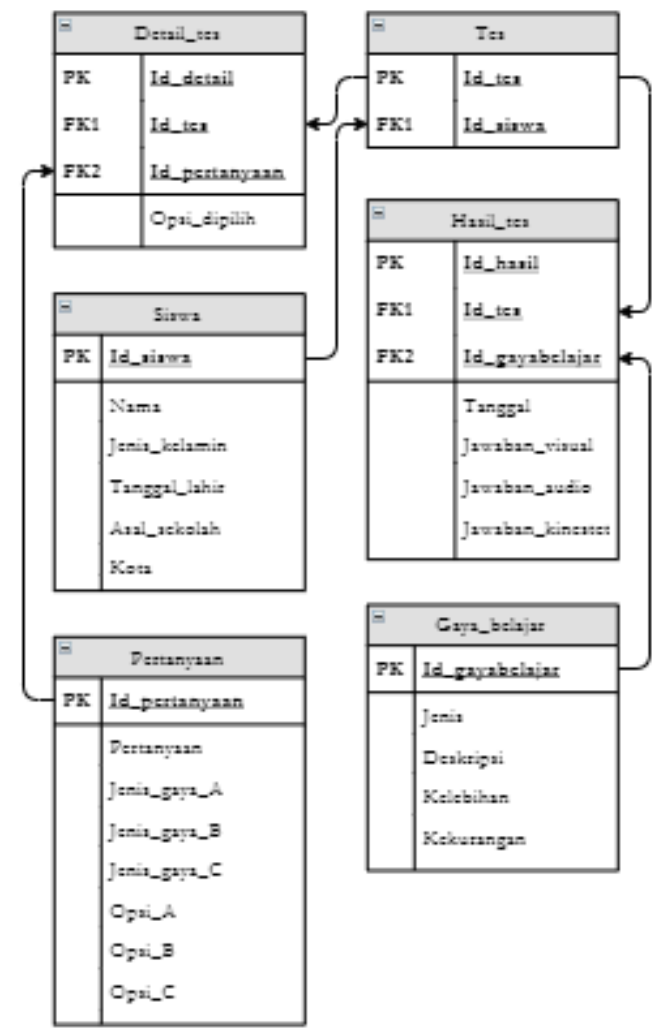

Gambar 4. Logical Record Structure

\subsubsection{Class Diagram}

Class diagram digunakan untuk menampilkan gambaran struktur system dari segi pendefinisian kelas-kelas dan paketpaket di dalam sistem dan memberikan gambaran secara statis dan relasi antar mereka. Rancangan Class diagram pada penelitian ini adalah sebagai berikut:

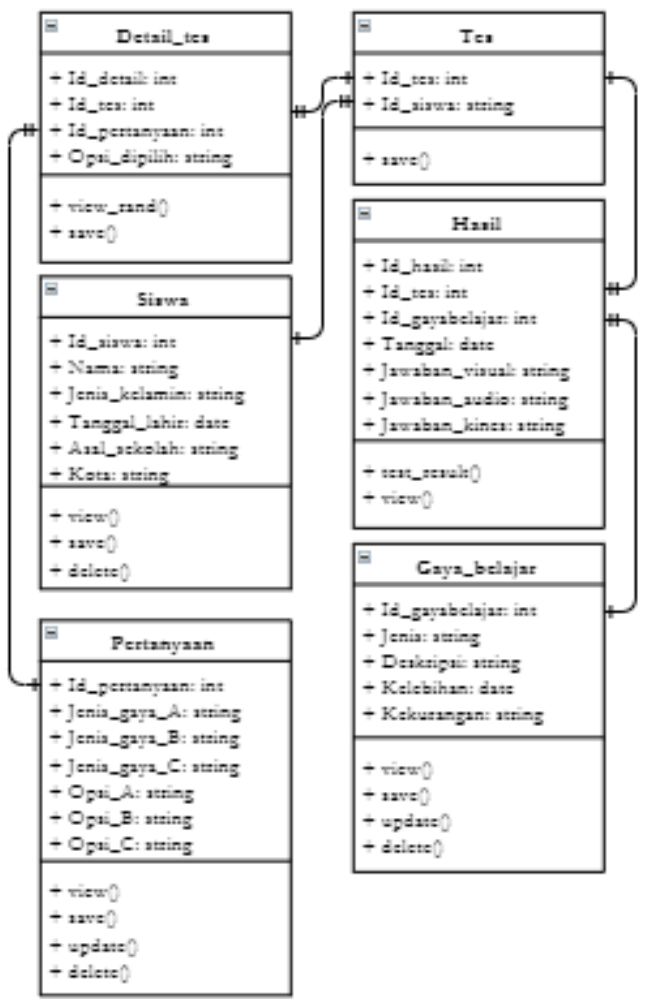

Gambar 5. Class Diagram

\subsection{Tampilan Antarmuka}

Tampilan interface yang dirancang pada sistem identifikasi terdiri dari beberapa menu dan halaman, berikut ini tampilan dari fungsi utama pada aplikasi yang dirancang.

\subsubsection{Beranda}

Halaman beranda akan tampil pada saat pertama kali website dibuka. Halaman ini menampilkan kata awalan dan menu pada bagian header.

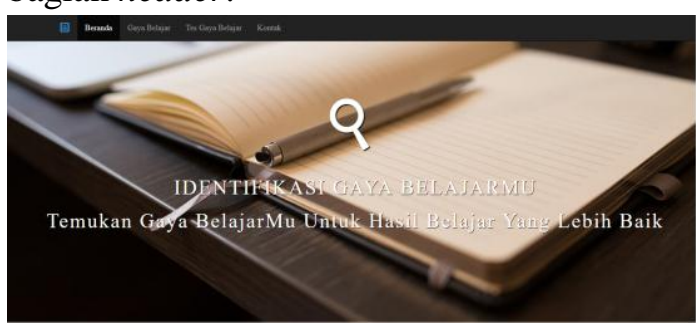

Gambar 6. Beranda

\subsubsection{Jenis Gaya Belajar}

Halaman jenis gaya belajar menampilkan informasi yang berkaitan dengan gaya belajar yang dibagi menjadi 3 . 
Halaman ini menjelaskan secara singkat tentang ketiga jenis gaya belajar.

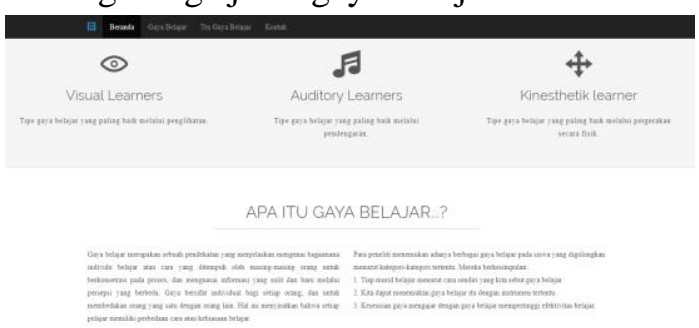

Gambar 7. Jenis Gaya Belajar

\subsubsection{Deskripsi Gaya Belajar}

Deskripsi gaya belajar menjelaskan jenis gaya belajar lebih detail, informasi yang disampaikan berkaitan dengan ciri-ciri dan kendala yang terdapat pada tiap jenis gaya belajar.

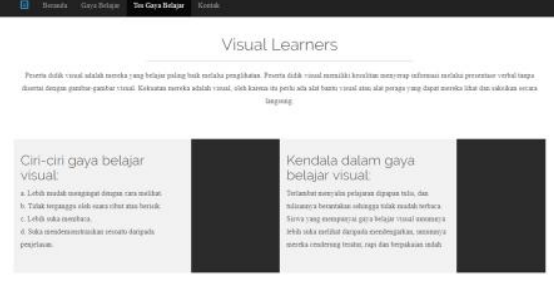

Gambar 8. Deskripsi Gaya Belajar

\subsubsection{Registrasi Sebelum Tes}

Halaman registrasi akan muncul ketika siswa akan melakukan tes identifikasi gaya belajar. Siswa wajib mengisi data diri terlebih dahulu. Informasi tersebut akan dipergunakan dan diolah oleh admin.

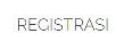

Gambar 9. Registrasi

\subsubsection{Pertanyaan Tes}

Pertanyaan tes adalah halaman yang menampilkan daftar pertanyaan secara acak, setiap jawaban memiliki bobot dari setiap jenis gaya belajar. Bobot gaya belajar yang paling besar adalah gaya belajar yang paling sesuai untuk siswa tersebut.
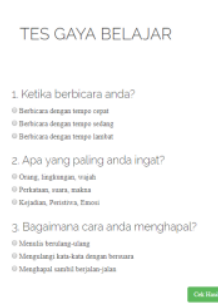

Gambar 10. Pertanyaan tes

\section{KESIMPULAN}

Berdasarkan apa yang telah dibahas pada penelitian, maka penulis menarik beberapa kesimpulan, yaitu:

1. Menghasilkan sebuah aplikasi identifikasi gaya belajar siswa. Dengan mengetaui gaya belajar yang sesuai, diharapkan siswa dapat menerapkan cara belajar yang paling berdasarkan hasil tes gaya belajar tersebut dan meningkatkan hasil belajar.

2. Aplikasi yang dihasilkan berbasis web yang dapat diakses oleh siapa pun tanpa adanya Batasan wilayah dan kriteria tertentu.

\section{SARAN}

Penelitian yang telah dibuat ini belum sepenuhnya sempurna, pengembangan aplikasi identifikasi masih bisa dikembangkan lagi kedepannya. Oleh karena itu peneliti memberikan beberapa saran, saran tersebut yaitu:

1. Membuat fasilitas konsultasi menggunakan media chatting kepada ahli dibidang pendidikan.

2. Membuat memberikan ruang guru pada aplikasi tersebut agar guru dapat mengetahui jenis gaya belajar siswasiswanya.

\section{DAFTAR PUSTAKA}

[1] R. W. Dahar, Teori-teori Belajar dan Pembelajaran, Indonesian. Jakarta: Erlangga, 2011.

[2] Slameto, Belajar dan Faktor-Faktor Yang Mempengaruhinya, Revisi. Jakarta: Rineka Cipta, 2010.

[3] S. B. Djamarah and A. Zain, Strategi 
Belajar Mengajar, Revisi. Jakarta: Rineka Cipta, 2006.

[4] M. N. Ghufron and R. Rismawati, Gaya Belajar Kajian Teoretik. Yogjakarta: Pustaka Pelajar, 2010.

[5] Hasrul, "Pemahaman Tentang Gaya Belajar," J. Medtek, vol. 1, no. 2, pp. 1-9, 2009.

[6] B. DePorter and mike Hernacki, QUANTUM LEARNING Membiasakan Belajar Nyaman dan Menyenangkan. Bandung: Kaifa, 2010.

[7] E. Gathrie and F. F. Brown, Educational Psychology. New York: Press Company, 1950.

[8] Y. Chania, M. Haviz, and D. Sasmita,
"Hubungan Gaya Belajar dengan Hasil Belajar Siswa pada Pembelajaran Biologi Kelas $\mathrm{X}$ SMAN 2 Sungai Tarab Kabupaten Tanah Datar," J. Sainstek, vol. 8, no. 1, pp. 77-84, 2016.

[9] Mardiana, Seni Menulis Ilmiah: Keselarasan Metode Dan Gaya Belajar. Makasar: Alauddin university, 2013.

[10] Nasution, Berbagai Pendekatan dalam Proses Belajar dan Mengajar. Jakarta: PT Bumi Aksara, 2008.

[11] Rusmono, Strategi Pembelajaran dengan Problem Based Learning itu Perlu: untuk meningkatkan Profesionalitas Guru. Bogor: Ghalia Indonesia, 2012.

[12] R. S. Pressman, The Incremental Model in Software Engineering, A Practitioner's Approach. New York: McGraw-Hill series in computer science, 2001. 